\title{
Uma orientação ecológica na abordagem das novas mídias e da comunicação
}

Palavras-chave: Pinto, Manuel-Entrevistas. Televisão e crianças. EducaçãoInovações tecnológicas.

Key words: Pinto, Manuel-Interviews. Television and children. EducationTechnological Innovation.

\section{Entrevista concedida por Manuel Pinto*, da Universidade do Minho, à Monica Fantin (UFSC).}

Revista Perspectiva: Apesar de as tecnologias digitais provocarem mudanças nos consumos de mídia, em países como o Brasil a TV ainda ocupa uma centralidade na vida de crianças e jovens. Como o senhor vê essa relação hoje?

Manoel Pinto: Vou falar da minha experiência na realidade portuguesa em particular e, de uma certa forma, da realidade europeia. Eu continuo a achar que a televisão mantém essa centralidade. Creio que há uma tendência de natureza etnocêntrica que faz com que os círculos que coabitam e convivem regularmente com a web, com as novas redes e as novas mídias tendam a extrapolar para a realidade no seu conjunto aquilo que é uma experiência que ainda acaba sendo relativamente minoritária. Essa é uma das dimensões do digital divide a que muitas vezes nos referimos e que não é suficientemente considerada.

Quando terminei a minha tese de doutorado em 1995, a internet começou a se tornar um fenômeno social e cultural muito significativo, e quando percebi a dimensão e o alcance desse novo ambiente, entrei um pouco em angústia por ter ficado três anos investigando em torno de "um meio que vai

\footnotetext{
* Professor Associado do Departamento de Ciências da Comunicação da Universidade do Minho, Diretor do Curso de Mestrado em Ciências da Comunicação - área de especialização Comunicação, Cidadania e Educação -, Vice-Presidente do Instituto de Ciências Sociais e Diretor Adjunto do Centro de Estudos da Comunicação e Sociedade da mesma universidade, em Braga, Portugal. Entrevista concedida à Monica Fantin (UFSC), na Universidade do Minho, Braga, em setembro de 2007.
} 
desaparecer". Mas sabemos pela história das tecnologias, que normalmente um novo meio não substitui o anterior e sim redefine relações, não só entre eles. A mesma coisa acontece com a televisão, apesar de todas as transformações importantes que têm ocorrido em torno das convergências, das novas plataformas e formas de produção e distribuição, do consumo e das relações das pessoas com a televisão.

Portanto, mesmo no formato de distribuição tradicional e mesmo em sociedades como as europeias, a televisão vai continuar a ocupar uma centralidade significativa. Estamos a assistir uma recomposição, uma emergência de novas práticas e uma diversificação de ocupação do tempo, das modalidades de acesso às mídias e com novas formas e oportunidades de produção de mídia. Estamos, portanto, num processo de recomposição, de reestruturação cujo alcance, ainda não sabemos qual vai ser.

Revista Perspectiva: O senhor poderia falar um pouco sobre a relação entre qualidade da televisão e sua importância como serviço público?

Manoel Pinto: Desse ponto de vista, na Europa nós temos uma televisão bem diferente da norte americana em particular, porque a televisão nasce como um serviço público, nasce como um aparelho estatal, um aparelho ideológico de estado, se quisermos usar essa terminologia. Este quadro começou a ser abalado a partir dos anos setenta, e o caso italiano foi precursor. Mas foi nos anos oitenta e noventa que a televisão começou a se abrir à iniciativa privada em numerosos países europeus, ainda que em vários casos a própria televisão estatal tivesse já uma presença forte ligada à dimensão comercial, nos casos em que a publicidade era uma das importantes fontes de financiamento.

Creio que nós continuamos a ter uma grande dificuldade em pensar o objeto televisivo. A televisão foi desqualificada culturalmente pela intelectualidade e de alguma forma nós desconsideramos dimensões significativas da realidade, que diariamente é ocupada e alimentada por mídias como a televisão. Isso tornou o pensamento crítico sobre o meio televisivo bastante débil. Essa foi uma conclusão da pesquisa que fiz. Além do mais, temos dificuldades em construir conceitos que sejam capazes de restituir e dar conta de dimensões que são fundamentais na experiência televisiva, como por exemplo, a relação entre o racional e o emocional. 
A experiência emocional é de novo "uma parente pobre", "uma louca da família" incontrolável, que não é pensada, e ao desconsiderarmos essa dimensão de uma experiência que é altamente presente, nós estamos a empobrecer o quadro reflexivo sobre essas experiências. Creio até que antes de fazermos uma reflexão sobre a qualidade em televisão, precisamos nos entender sobre o problema conceitual da televisão, sobre a análise desse objeto que é muito mais complexo do que supomos. Projetamos para ele dimensões e funções que por ventura não lhe cabem, e como partimos de pressupostos que muitas vezes não são pertinentes, acabamos por tirar conclusões enviesadas, ou pelo menos arriscadas, sobre a natureza e o papel cultural desse meio.

Desse ponto de vista, estamos ainda a tatear demasiado, temos pouca riqueza do pensamento sobre o meio televisivo. Por isso no centro de pesquisa que dirijo aqui na Universidade do Minho nós tentamos reforçar essa linha de trabalho com dois vetores importantes de estudo. Um, centrado na produção informativa da televisão, do seu papel de acompanhamento da atualidade; e outro voltado para uma programação para a infância. Parecem-nos duas vertentes, do ponto de vista do papel cívico e do papel cultural da televisão, que também podem ser analisadas. Curiosamente, estes estudos surgem de uma conclusão de estudos anteriores que eu fiz na minha tese e que a minha colega Sara Pereira fez no seu mestrado ao estudar os contextos da recepção com crianças em idade pré-escolar. No fim desse trabalho, concluímos que o quadro de compreensão ficava pobre se não incorporássemos uma elaboração sobre os operadores, as estratégias dos operadores, as lógicas de programação, as características, os conteúdos, o modo como os operadores se relacionam com o contexto e com a sociedade. Assim, tivemos a oportunidade de criar duas linhas importantes de investigação que remontam ao inicio da televisão em Portugal, uma voltada para as questões da informação jornalística, coordenada por Felisbela Lopes, e outra mais voltada para as lógicas de programação para os mais pequenos.

Revista Perspectiva: Num momento em que as mídias vão protagonizando cada vez mais as relações entre as pessoas, o senhor tem falado sobre a importância de distinguir o essencial de secundário, que seria a questão do uso de ferramentas e instrumentos e a questão dos objetivos e das 
finalidades, abrindo espaço para o que seria uma terceira via. Poderia falar um pouquinho sobre essa terceira via?

Manoel Pinto: Aqui há um aspecto que tem me preocupado bastante e tem a ver com aquilo que na Europa temos vindo a denunciar como uma deriva tecnológica da Educação para os Meios. Trata-se de uma abordagem redutora, centrada nas tecnologias e nos softwares, muito do agrado de alguns governos que encontram assim algo de visível, de material e de mediatizável para mostrar e para inaugurar em eventos específicos. Por que um político, quando lança um programa crítico de Educação para os Meios, eventualmente vai fazer um discurso, mas se ele tiver laboratório, computador para entregar, isso é muito mais visível, passa no telejornal, enche mais o olho.

Esta orientação, funcional aos interesses das grandes indústrias de hardware e software reduz a Educaşão para os Meios a uma questão de acesso e uso, que não coloca as questões do sentido, nem incorpora a dimensão crítica, incluindo a própria tecnologia. Ou seja, não faz da tecnologia um objeto de interrogação. Ora, eu creio que há aqui um risco tremendo, porque é o sistema a consagrar toda a carga mitológica da tecnologia como se ela fosse dotada de um poder intrínseco, como se fosse um deus ex-machina capaz de, por si só, mudar a realidade e a vida.

E desse ponto de vista eu costumo convocar um poeta Português do séc. XVIII, Bocage. Ele era um repentista, alguém a quem se encomendavam rimas ou quadras. Conta-se que um dia, em um café de Lisboa, uns bandidos o surpreenderam à saída, dizendo que lhe poupariam a vida se ele respondesse a três perguntas: "Quem tu és? De onde tu vens? E para onde tu vais?” Ao que ele respondeu: "Sou Bocage, venho do café Nicola, e vou para o outro mundo se disparares a pistola". Nessa história as perguntas é que são interessantes. Eu acho que a pergunta "quem somos nós" revela as pessoas que aprendemos a ser e com quem nos relacionamos. "De onde viemos" implica a memória, a história, a trajetória de vida e o que fizemos. E "para onde vais" é o modo que queremos fazê-la, essa dimensão de percurso e não apenas o carpe diem ou o imediato, é ao mesmo tempo o que sonhamos, o que queremos, aquilo que projetamos, e queremos fazer juntos. Creio que estas são as grandes questões da alfabetização midiática, pois sem elas ou à margem delas eu não acredito que seja possível. E mais, 
penso até que pode ser perigoso, pode ser manipulador, adestrador para fabricar potenciais clientes e consumidores desse sistema em geral e das tecnologias em particular. Nesse sentido seriam os governos a criarem um mercado para as grandes multinacionais do varejo do software. Eu me dei conta desse fenômeno quando em 1989 o Conselho da Europa organizou na Turquia uma reunião de ministros da educação sobre esta matéria. O encontro era sobre a Educação para os Meios, mas os ministros e os relatórios em que se apoiavam falavam majoritariamente de tecnologias na educação. Eu disse "Que coisa está a passar que eu não entendo?” Portanto esse é um paradigma que está a marcar, por exemplo, muitas políticas comunitárias. Há alguns anos, fiz uma análise dos discursos dos programas sobre tecnologia na educação, internet na escola etc., em Portugal e o que constatei foi exatamente isso: a importância do uso, de saber usar, de poder ter acesso. Foi um discurso em que a Educação para os Meios era vista como uma mera roupagem para um projeto modernizador para Educação para os Meios, que ficava altamente funcional, mesmo que não voluntariamente. Essas coisas são frutos de convergências de interesses diversos que conjunturalmente se conjugam, mais do que uma aliança estratégica, quero pensar. Não sigo, portanto, visões conspiracionistas, segundo as quais "há uma grande aliança entre os poderes em que a União Europeia e os grandes monopólios, os grandes grupos transnacionais querem fazer a cabeça das criancinhas e manipular a opinião pública”. Mas objetivamente há aqui uma conjugação de interesses que favorecem uma determinada estratégia nas políticas educativas.

Portanto qual é o lugar do pensamento critico e de uma abordagem crítica? Penso que ela vai continuar sendo uma abordagem relativamente marginal. Falando da Europa e do conhecimento que eu tenho ao nível dos países europeus, creio que os programas, os projetos e as iniciativas que vem sendo tomadas nos últimos 10 anos, normalmente são um enfeite, um habitué dos programas oficiais, que são muito marcados por essa preocupação modernizadora e, no fundo, essencialmente mercantil.

Revista Perspectiva: Se não podemos perder de vista a natureza instrumental da técnica que é permeada por contradições, visto que essa lógica da produção que ainda impera é a do capital e do consumo, seria possível pensar esse uso sem incorrer na lógica do mercado? 
Manoel Pinto: Eu não sou contra o mercado nem sou contra que haja outros interesses que se movimentem nesse espaço. Isso faz parte. Obviamente temos que ter atenção e conhecer a realidade para não sermos marionete de um jogo que não controlamos e que porventura nem vemos. Essa visão esclarecida sobre quais são os grandes interesses que se jogam neste terreno é fundamental, mas temos que saber trabalhar com aquilo que Michel de Certeau fala, que é a capacidade de saber tirar partido, de desenvolver uma capacidade de movimentação tática. Um dos grandes desafios hoje para a Educação para os Meios é não nos submeter à agenda que eles querem nos impor e incorporar questões que alarguem essa agenda oficial, que parece quase natural.

Portanto defendo uma postura de crítica não isolacionista - porque aí também há o risco de pretender "criar o céu na terra", o risco do purismo, do fundamentalismo que é o contrário e também é perverso porque descontextualiza a realidade -, e que seja capaz de capacitar a voz das pessoas. Por exemplo, somos nós que estamos a alimentar os conteúdos dessas ferramentas como blogs, wikis, youtube, etc., mas os que detêm essas ferramentas utilizam os nossos conteúdos para fazer circular a publicidade, e precisamos negociar com eles e começar a criar os mundos nossos. Outros estão a utilizar esses nossos conteúdos vendendo a outros anunciantes. É preciso não perder isso de vista, senão vai ser como o filme Truman Show, ${ }^{1}$ em que vivemos numa redoma e não percebemos que há outros mundos, que há mais mundos além do qual vivemos.

Revista Perspectiva: No encontro da UNESCO, em junho de 2007, em Paris, falou-se dos avanços, obstáculos e das tendências da Mídia Educação, 25 anos depois de Grünwald, e foi discutido que os avanços teóricos nem sempre foram acompanhados de avanços na prática. E agora se discute a respeito do que seria uma New Media Education, com o argumento que a mídia digital demanda novos pressupostos, numa espécie de correção de paradigma ou um novo entendimento para a Mídia Educação. Alguns estudiosos acreditam que a abordagem crítica daria lugar a uma perspectiva de produção criativa. O senhor compartilha deste argumento?

Manoel Pinto: Daquilo que eu sei e consigo enunciar, que é pouco, é que daqueles três pilares da Educação para os Meios: os meios como recurso 
pedagógico, como tema de indagação e estudo; e como campo de expressão e comunicação. O primeiro aspecto é indispensável, que é tirar partido dos meios como recurso educativo. Mas é preciso fazer também dos meios, um meio de discussão e um meio que dê voz a esta discussão. Essa última vertente hoje adquiriu uma potencialidade muito maior.

Mas não é por nós produzirmos muito, que somos mais críticos e nos comunicamos melhor. Ou seja, nenhuma destas vertentes por si só assegura grandes mudanças. Não é por compreender melhor que me comunico melhor. Não é por escrever muito, por fazer um texto, por colocar vídeos no youtube que eu vou viver melhor. Eu posso até mesmo criar mundos que me satisfazem, numa espécie de narcisismo digital, agora com potencial de desenvolvimento em larga escala. Somos grandes narcisistas que se satisfazem ao ver-se publicado, a produzir e a olhar o seu próprio trabalho, não é? Esse narcisismo também tem que ser objeto de interrogação e entrosamento com os processos que são síntese disso, das relações sociais, naquilo que somos, nós com os outros. Aí a gente vê o pouco avanço, a pouca novidade. Lendo as notícias dos cadernos especiais sobre as novas tecnologias, ali não se tocam nessa dimensão. De fato ela remete para um tempo longo, que exige maturação, silêncio e distanciamento.

Então, não me parece que seja uma grande mudança de paradigma. Para ser franco, não me parece que haja aqui um novo paradigma, e sim um quadro cultural muito mais fragmentário, marcado pelo que se chama mash-up, mistura, combinação que torna difícil até a legibilidade do mundo. Viemos de uma tradição cartesiana de ideias claras e distintas, e hoje vemos os filhos fazer trabalho de escola em casa assistindo televisão. Esse tipo de lógica combinatória, essas misturas e certa convergência, se é que esse termo não pode parecer abusivo, define um quadro bastante diverso. Creio que é um quadro cultural de vivências, de relações que criam novos desafios e que nós podemos desencadear.

Mas o que é ser crítico num quadro deste? Acho que pode ter mais alcance do ponto de vista da investigação, da reflexão em que está emergindo um novo paradigma, porém eu ainda não o vejo. Por exemplo, eu não sei o que está sendo feito com as novas ferramentas, o que os jovens estão a fazer com os blogs, com o youtube, com o celular? Está a emergir algo novo? 
Os programas, os projetos e as propostas das instituições são novas? Há alguma coisa de muito novo que esteja a emergir aí?

No entanto, há uma ideia que tenho trabalhado que é a volta das questões ambientais, de um novo espírito de ambientalismo que seja capaz de cruzar o biofísico e o biossocial com o simbólico. Importa questionar a clivagem que tendemos a fazer entre o simbólico e o resto da vida: também nos deve preocupar a qualidade do ar simbólico que criamos e respiramos, o risco de contaminação existente, o desenvolvimento sustentável que podemos construir aí. A dimensão simbólica e o ambiente que configura têm força suficiente para destruir o planeta, pelo que vale a pena preocupar-se com ela. Ora a mídia é hoje a principal instância de produção simbólica de nossas sociedades.

Vale, por isso, a pena alargar as nossas concepções de ambientalismo e ecologia e desafiar ecologistas a incorporarem uma nova agenda para essa questão do simbólico, que é o digital mas é também o analógico. Há dimensões da vida que não são redutíveis a "zeros e uns", que precisam de outros ritmos e de múltiplos tempos.

Revista Perspectiva: É aquela dimensão do tempo necessário para decantar certas ideias. E de novo a pergunta: em que medida isso está nos tornando mais felizes?

Manoel Pinto: Exatamente isso. Creio que talvez precisemos recuperar certos autores que já no passado formularam ideias que podem ser úteis hoje. Um deles, curiosamente, é um paleontólogo e teólogo, Pierre Teilhard de Chardin. Era jesuíta e teve sérias dificuldades com a hierarquia da Igreja. Ele trabalhou uma parte de sua vida na China. Era um poeta, um criador e a ciência para ele é quase sempre poesia. Ele tem uma literatura muito vasta, e como teólogo, escreveu a Missa sobre o mundo, ${ }^{2}$ em que ele contempla a energia toda do planeta e imagina o mundo e a vida como série de camadas, como esferas, bioesfera, socioesfera e também uma noosfera, uma espécie de camada envolvente da terra relativa à criação, ao espiritual - a arte, as religiões, os conhecimentos, a informação, a sabedoria. Uma espécie de espaço de respiração. Há vários ecologistas que acompanham essa ideia de noosfera, como por exemplo, Gregory Bateson, com a ecologia da mente, que também é um autor que trabalha com essa noção de ambiente, de 
nova ecologia. ${ }^{3} \mathrm{E}$ depois há autores que trabalham essa noção aplicada às tecnologias e às novas mídias numa orientação ecológica na abordagem da comunicação.

Revista Perspectiva: Em países como o Brasil, em que ainda não foram resolvidas as questões básicas da escolaridade, no sentido da apropriação significativa da leitura e da escrita que permite a condição de estar alfabetizado, alguns estudiosos avaliam que estejamos passando de uma cultura oral para uma cultura digital sem ter a cultura escrita apropriada. Como o senhor analisa esta situação?

Manoel Pinto: Em primeiro lugar, este problema também é sentido cada vez mais nas sociedades ditas avançadas, apesar de ser em uma escala diferente. O problema das migrações hoje coloca questões desta natureza de exclusão e de dificuldade de enquadramento e aprendizagem no coração das cidades ditas desenvolvidas e industrializadas de países como França, Itália, Espanha, Portugal e Alemanha. A imigração diária dos países asiáticos e da ex-União Soviética coloca questões impressionantes, como o isolamento linguístico, cultural e das literacias básicas. Muitos desses imigrantes vivem uma situação de solidão e essa exclusão vai se dando de uma forma muito mais dramática e em escalas diferentes. Parece que esse problema hoje é geral.

Conheci algumas experiências em favelas do Rio de Janeiro em que se procurava ir por essa via e me pareceu bastante interessante, visto que as crianças hoje são socializadas primeiro pela TV, num universo que já lhe é outro, e tendo acesso à oportunidades que lhes permitam adquirir competências e as capacite para ter a sua voz, para vir a ser sujeitos a comunicar melhor, poderia, eventualmente, ser uma etapa para se chegar lá.

Revista Perspectiva: Por outro lado, ainda há certa resistência da escola e de alguns educadores em fazer uso significativo dos meios e das tecnologias na prática pedagógica e a estudarem esse objeto, o que se reflete também na ausência da Mídia Educação durante a formação universitária. Como a Educação para os Meios está presente na formação de professores em Portugal?

Manoel Pinto: Há uns dez anos acompanhei uma pesquisa de mestrado que era justamente perceber como a Educação para os Meios estava presente nos 
currículos dos professores e ela aparecia de forma muito discreta, sempre em currículos sobre tecnologias, com exceção de três ou quatro escolas, onde havia uma perspectiva de construção de autonomia crítica em torno do que se chama Educação para os Meios. Portanto, a lógica global era a de uma perspectiva da Tecnologia da Educação ou Tecnologia Educativa. Neste momento, com a mudança do Processo de Bologna, vamos ter de desafiar alguém a pesquisar o que é que foi introduzido ou retirado, mas creio que a situação portuguesa, desse ponto de vista ainda é uma situação muito pobre, de um país periférico que às vezes se contenta com aquele discurso de que é preciso reforçar a matemática e a língua em detrimento das dimensões artístico-expressivas e das dimensões culturais, que são tão vitais quanto as outras.

Revista Perspectiva: O senhor considera que a abordagem da Educação para os Meios em Portugal teria alguma especificidade em relação a outros países europeus?

Manoel Pinto: Eu acho que estamos numa situação em que não podemos nos dar a esse luxo. Se pudermos ter mestrados que criam oportunidades de olhar sobretudo as pessoas e outro tipo de agentes sociais, de os capacitar para compreender e intervir nessa dimensão tão relevante do nosso ambiente cultural, eu creio que já seria ótimo, mesmo porque os recursos humanos são escassos.

Revista Perspectiva: Para finalizar, o senhor poderia falar um pouco sobre a pesquisa que está desenvolvendo atualmente?

Manoel Pinto: Eu costumo dizer que "tenho ideia para os outros", por que o tempo é limitado, e a consciência dos limites ainda vai sendo possível dentro dos próprios limites... Juntamente com Sara Pereira, temos uma pesquisa encomendada por uma entidade que tem funções legais e constitucionais do ponto de vista de monitorar e calcular a programação voltada aos pequenos e assim poder fazer com que os operadores televisivos cumpram com o que a lei da televisão dispõe para públicos vulneráveis. Numa primeira etapa estamos criando uma metodologia e instrumentos de investigação para fazer a monitoração da programação para a infância no próximo ano. Vamos fazer uma análise da programação geral, os espaços e 
tempos, as lógicas que os operadores usam para colocar a programação em diferentes momentos, embora sabendo que a programação das crianças não é necessariamente aquela que os operadores lhes destinem, mas aquela que elas veem. Pensamos que é um trabalho completamente novo em Portugal. Vamos sedimentar a análise partindo de nossa concepção de que a relação das crianças com a televisão e com as mídias implica necessariamente que ela seja não apenas objeto mas parceira também.

\section{Notas}

1 NT: O filme The Truman show, (Peter Weir, EUA, 1998), traduzido no Brasil por O Show de Truman: o show da vida, trata da história de Truman Burbank, um vendedor de seguros que desde que nasceu vive vigiado por câmeras de televisão. Sem saber que é a estrela de um reality show, é o único personagem de uma trama da vida real que não sabe o que está acontecendo, pois tudo o que ocorre ao seu redor é fictício (seu emprego é criação, seu casamento é uma farsa e seus amigos estão apenas cumprindo um contrato como atores da rede de televisão que transmite o "Show de Truman"). Truman descobre a farsa quando uma câmera cai do alto dos cenários, e então passa a desconfiar de tudo e todos numa incessante busca pelos olhos eletrônicos que o monitoram.

2 NT: Obra de Teilhard de Chardin escrita em 1923.

3 NT: Ver: BATESON, Gregoy. Steps to an Ecology of Mind, Chicago: University of Chicago Press, 1972; BATESON, Gregoy. Mind and Nature. A necessary Unity. New York: Dulton, 1979. 


\section{Manuel Pinto}

Dpto. Ciências da Comunicação - Instituto de Ciências Sociais da Universidade do Minho

4700-057 - Braga, Portugal

Tel: +351 253604214

E-mail:mpinto@ics.uminho.pt

\section{Monica Fantin}

Centro de Ciências de Educação, Universidade Federal de Santa Catarina, UFSC Programa de Pós-Graduação em Educação

Florianópolis/SC - CEP 88040-900

Tel: + 48 32332759/84121285

E-mail:mfantin@terra.com.br 